\title{
PENCARIAN JALUR TERDEKAT MENUJU RUMAH SAKIT DI KOTA BOGOR DENGAN MENGGUNAKAN ALGORITMA A*
}

\author{
Erniyati, M. Kom ${ }^{1}$, Mulyati, M. Kom ${ }^{2}$ \\ 1, 2) Program Studi IImu Komputer, FMIPA, Universitas Pakuan, \\ Bogor, Indonesia
}

Corresponding Author: neny erniyati@yahoo.com

Article history: received 2 Desember 2018; revised 15 Desember 2018; accepted 28 Desember 2018

\begin{abstract}
Abstrak
Pencarian jalur terpendek (shortesh path) merupakan salah satu solusi dalam pencarian suatu lokasi yang terdekat jika terdapat beberapa jalur yang dapat dilaluinya. Seperti halnya dalam pencarian rumah sakit di kota Bogor. Kota Bogor merupakan kota yang cukup luas dan memiliki jalur yang cukup banyak. Untuk mencapai rumah sakit yang dituju dibutuhkan informasi jalur terdekat guna meminimalisir biaya dan waktu yang lebih efisien. Ada beberapa algoritma yang bisa digunakan untuk pencarian jalur terdekat diantaranya yaitu algoritma $A^{*}$ (star), algoritma ini membuang langkah-langkah yang tidak perlu dengan pertimbangan bahwa langkah-langkah yang dibuang sudah pasti merupakan langkah yang tidak akan mencapai solusi yang diinginkan. Sistem ini selanjutnya dihubungkan dengan perangkat mobile yang berbasis android. Dengan menerapkan Algoritma $A^{*}$ (star) diharapkan dapat membantu dalam mencari dan menentukan lintasan terpendek sehingga didapat suatu jalur yang optimal untuk mencapai rumah sakit di Kota Bogor.
\end{abstract}

Keywords : algoritma $A^{*}$, android, jalur terpendek, rumah sakit.

\begin{abstract}
The shortest path searching is one of some solutions for finding a locaton which is closest if there are several alternative paths that can be passed. It is similar with the case in searching for hospitals in the city of Bogor. Bogor is a city that is quite large and it has a number of routes. To reach the hospital destination, it needs information of the shortest path to minimize the cost and time eficency. There are several method of algorithm can be implemented for this case, and the $A^{*}$ (star) algorithm is one of the solution. This algorithm will discard unnecessary steps which are definitely not as a solution. This system is then linked to an Android-based mobile device. By applying the $A$ * (star) algorithm, it is expected to be able to help in finding and determining the shortest path with an optimal path to reach the hospital in the city of Bogor.
\end{abstract}

Keywords : algorithm $A^{*}$, android, shortest path, hospital

\section{Pendahuluan}

Pencarian jalur terpendek (shortesh path) merupakan salah satu solusi dalam pencarian suatu lokasi yang terdekat jika terdapat beberapa jalur yang dapat dilaluinya. Seperti halnya dalam pencarian rumah sakit di kota Bogor. Jika sedang mengalami keadaan darurat atau butuh pertolongan karena sakit, maka pencarian rumah sakit yang terdekat sangat dibutuhkan.

Kota Bogor merupakan kota yang cukup luas dan memiliki jalur yang cukup banyak. Untuk mencapai rumah sakit yang dituju dibutuhkan informasi jalur terpendek guna meminimalisir 
biaya dan waktu yang lebih efisien. Salah satu penentuan jalur lintasan terbaik adalah dengan mencari jalur terpendek. Jalur terpendek dapat dihitung dengan menggunakan teori graph.

Menurut teori graf, persoalan lintasan terpendek adalah untuk mencari lintasan antara dua buah simpul pada graf berbobot yang memiliki gabungan jumlah nilai bobot pada sisi graf yang dilalui dengan jumlah paling minimum. Persoalan lintasan terpendek paling banyak ditemui yaitu dalam bidang transportasi, seperti pada pencarian rute terpendek untuk menempuh dua kota [1].

Ada beberapa algoritma yang bisa digunakan untuk pencarian jalur terdekat diantaranya yaitu algoritma $A^{*}$ (a star), algoritma ini membuang langkah-langkah yang tidak perlu dengan pertimbangan bahwa langkah-langkah yang dibuang sudah pasti merupakan langkah yang tidak akan mencapai solusi yang diinginkan [2].

Saat ini untuk pencarian jalur terdekat menggunakan google map ataupun GPS (Global Position System), GPS yang tersedia di aplikasi digunakan untuk menentukan jarak pengguna dengan tempat yang ingin dituju [3]. Namun di google map belum dapat merekomendasikan jalur mana yang terdekat menuju ke tujuan. Oleh karena dengan menerapkan Algoritma $A^{*}$ (star) diharapkan dapat membantu dalam mencari dan menentukan lintasan terpendek sehingga didapat suatu jalur yang optimal untuk mencapai tujuan.

Algoritma $A^{*}(A$-Star) merupakan suatu algoritma yang termasuk pada kategori metode pencarian yang memiliki informasi (informed search method). Algoritma $A^{*}$ (A-Star) menggunakan estimasi jarak terdekat (cost/ jarak sebenarnya) untuk mencapai tujuan (goal) dan memiliki nilai heuristik yang digunakan sebagai dasar pertimbangan pemilihan jalur [4]

Algoritma $A^{*}$ ini memeriksa node dengan menggabungkan $g(n)$, yaitu cost yang dibutuhkan untuk mencapai sebuah node dan $h(n)$ yaitu cost yang didapat dari node ketujuan [5]. Sehingga dapat dirumuskan sebagai berikut:

$$
f(n)=g(n)+h(n)
$$

$f(n)=$ perkiraan total cost terendah dari setiap path yang akan dilalui dari node $\mathrm{n}$ ke node tujuan.

$g(n)=$ biaya yang sudah dikeluarkan dari keadaan awal sampai keadaan $n$

$h(n)=$ perkiraan heuristic atau cost atau path dari node $n$ ke tujuan.

Untuk menentukan nilai $h(n)$ ditunjukan oleh persamaan :

$$
h(n)=\sqrt{(X n-X g o a l)^{2}+(Y n-Y g o a l)^{2}}
$$

dimana :

$h(n) \quad=$ nilai heuristik untuk node/ titik $n$

$X n=$ nilai koordinat Xdari node/titik $n$

$Y n=$ nilai koordinat Ydari node/ titik $n$

Xgoal = nilai koordinat Xdari node/titik tujuan

Ygoal = nilai koordinat Ydari node/ titik tujuan

Adapun langkah-langkah dalam pencarian jalur terpendek dengan algoritma $\mathrm{A}^{*}(A-S t a r)$ sebagai berikut [6]:

1. Masukan node awal ke openlist.

2. Lakukan perulangan langkah-langkah berikut :

- Cari node (n) dengan nilai $f(n)$ yang paling rendah dalam openlist. Node ini sekarang menjadi current node.

- Keluarkan current node dari open list dan masukan ke close list.

- Untuk setiap tetangga dari current node lakukan langkah berikut:

1. Jika tidak dapat dilalui atau sudah ada dalam close list, abaikan.

2. Jika belum ada di open list. Buat current node parent dari node tetangga. Simpan nilai $f(n), g(n)$ dan $h(n)$ dari node ini.

3. Jika sudah ada di open list, cek bila node tetangga ini lebih baik, menggunakan nilai $g$ sebagai ukuran. Jika lebih baik ganti parent dari node ini di open list menjadi current node, lalu kalkulasi ulang nilai $g$ dan $f$ dari node ini.

Hentikan perulangan jika:

1. Node tujuan telah ditambahkan ke open list, yang berarti rute telah ditemukan. 
2. Belum menemukan node goal sementara open list kosong yang berarti tidak ada rute.

3. Simpan rute. Secara backward, urut mulai dari node goal ke parent masing-masing sampai mencapai node awal sambil menyimpan node kedalam sebuah array.

\section{Metode Penelitian}

Metode Penerapan algoritma $A^{*}$ (A-Star) untuk mencari rute Rumah Sakit di kota Bogor berbasis android ini dibuat secara bertahap menggunakan model System Development Life Cycle (SDLC) [7]. Model SDLC mengusulkan sebuah pendekatan kepada perkembangan perangkat lunak yang sistematik dengan tahapan perencanaan sistem, analisis sistem, perancangan, implementasi dan uji coba.

Metode Pengumpulan Data

Pada metode pengumpulan data dilakukan studi kepustakaan dan studi langsung.

1. Studi Pustaka

Pada metode ini hal yang dilakukan adalah mengumpulkan dan mempelajari buku-buku yang berhubungan dengan masalah yang dibahas dalam pengembangan aplikasi.

2. Studi Lapang

Pada metode ini dilakukan teknik Observasi (Pengamatan).

Pada metode observasi, dilakukan penelitian langsung ke salah satu RS di kota Bogor untuk memperoleh dan mengumpulkan data yang dibutuhkan,beserta meninjau langsung kondisi jalan yang dilewati dan kemacetan yang dialami pada saat proses observasi.

\section{System Development Life Cycle (SDLC)}

Metode yang digunakan dalam melaksanakan penelitian menggunakan pola system development life cycle (SDLC). Tahapan pembuatan aplikasi disajikan secara lengkap pada Gambar 1 di bawah ini:

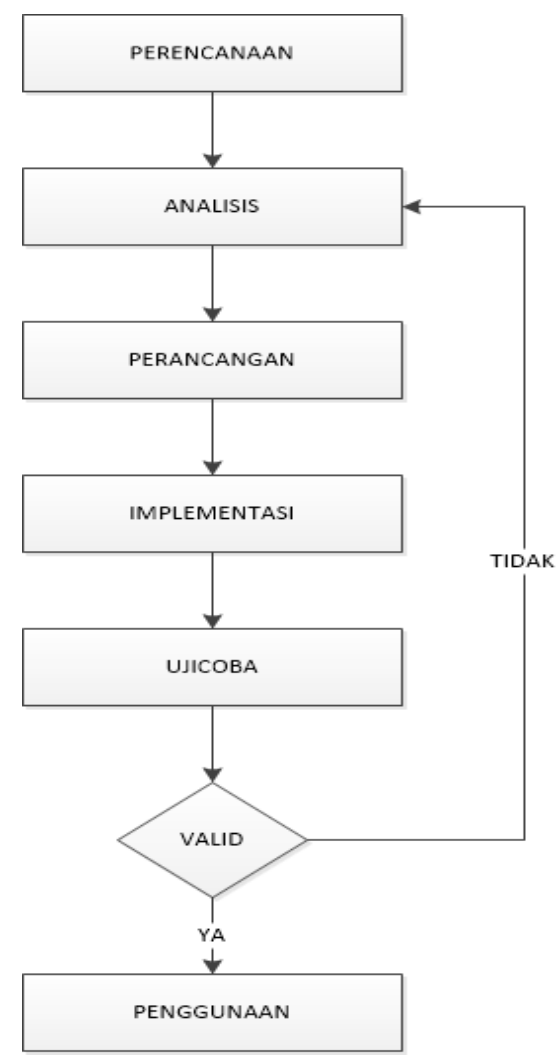

Gambar 1 Pendekatan SDLC 
Tahap perencanaan sistem adalah tahap awal untuk mendapatkan resources yang digunakan untuk memperoleh solusi pada sistem yang akan dibuat. Sistem yang akan dibuat adalah sistem pencarian jalur terdekat Rumah Sakit di kota Bogor dengan menggunakan metode $A^{*}(A$-Star). Sistem ini menerapkan cara melebar ke setiap jalur pada level yang sama, untuk menemukan rute terbaik dari titik awal sampai tujuan.

\section{Tahap Analisis}

Tahap analisis sistem adalah tahap setelah perencanaan dan tahap sebelum perancangan. Tahap analisis sistem merupakan tahap menganalisis permasalahan mengenai jalur terdekat dari satu titik ke titik yang lainnya dengan menggunakan metode $A^{*}$ (A-Star) guna mendapatkan jalur terbaik saat proses pengiriman barang berlangsung.

\section{Tahap Perancangan}

Tahap perancangan dilakukan guna memudahkan tahapan berikutnya yakni implementasi, tahap perencanaan mencakup rancangan flowchart view, strukturnavigasi serta design screen. Didalam tahap perancangan sistem dibuat secara logika dengan menggunakan informasiinformasi yang telah terkumpul dalam bentuk data dan telah dilakukan analisis.

\section{Tahap Implementasi}

Tahap implementasi sistem merupakan suatu proses transformasi hasil perancangan kedalam bahasa pemrograman yang akan digunakan. Hal ini termasuk penulisan kode program yang dimengerti oleh mesin komputer, adapun bahasa pemrograman yang digunakan adalah java dan menggunakan perangkat lunak pendukung lainnya sebagai pendukung.

\section{Tahap Uji Coba}

Uji coba sistem adalah pengujian yang dilakukan setelah pembuatan sistem selesai dibuat dengan melakukan percobaan pada user interface.

\section{Hasil dan Pembahasan}

Adapun hasil penelitian yang diperoleh adalah terbentuknya aplikasi pencarian jalur terdekat menuju rumah sakit di Kota Bogor, dalam aplikasi ini hasilnya adalah berupa rekomendasi rumah sakit yang terdekat dengan pengguna. Gambar 2 berikut ini adalah hasil tampilannya utama aplikasi:

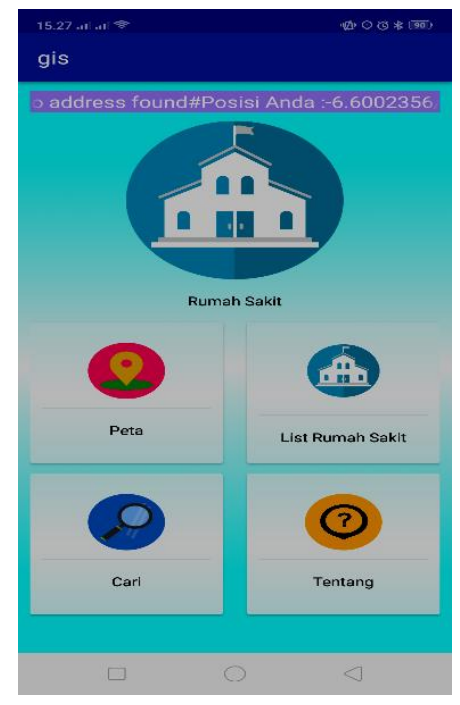

Gambar 2. Tampilan utama Aplikasi

\section{Halaman tampilan daftar Rumah Sakit}

Halaman tampilan daftar Rumah Sakit adalah halaman yang menampilkan informasi rumah sakit dikota Bogor yang meliputi rumah sakit salak, RS Islam Bogor, Siloam, Bogor Medical 
KOMPUTASI (Jurnal IImiah IImu Komputer dan Matematika)

Vol.16, No.1, Januari 2019, Hal. 235 - 253

P-ISSN: 1693-7554, E-ISSN: 2654-3990

Center (BMC), RS Umum Daerah Bogor, RS PMI, RS Mulia Pajajaran dan rumah sakit Hermina, berikut tampilan halamannya pada Gambar 3.

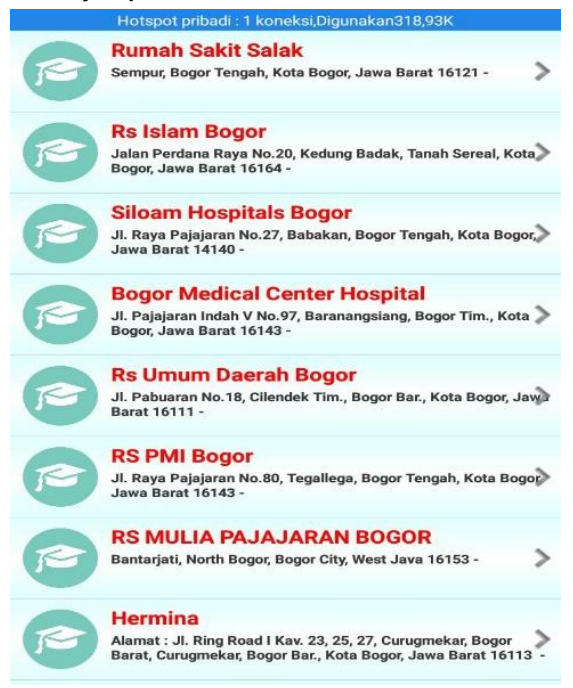

Gambar 3. Halaman Daftar Rumah Sakit

\section{Halaman tampilan lokasi Rumah Sakit}

Halaman tampilan lokasi Rumah Sakit berisi lokasi masing-masing Rumah Sakit seperti diperlihatkan pada Gambar 4, tampilan lokasi ini diperoleh dari pencarian dengan menggunakan Google Map

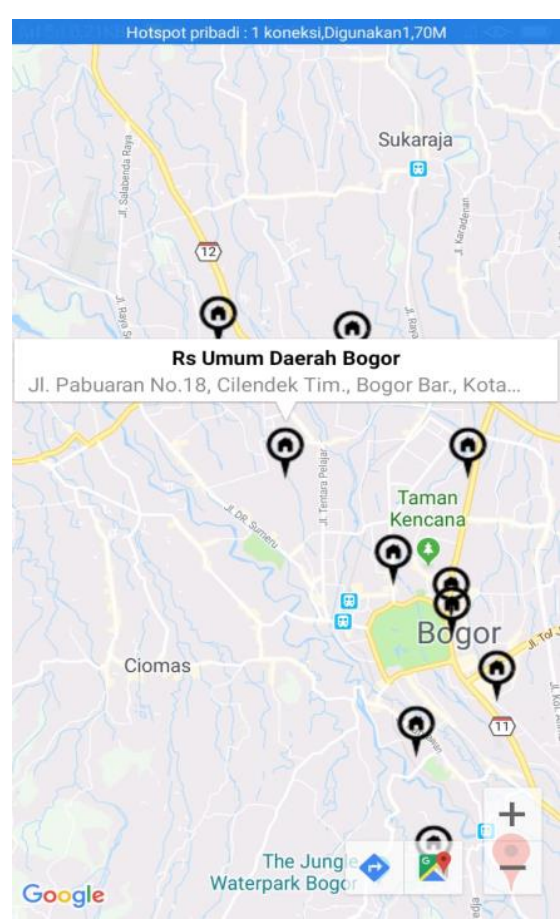

Gambar 4. Tampilan lokasi rumah sakit

Tahap berikutnya adalah uji coba sistem, pengujian sistem dilakukan untuk melihat apakah algoritma $A^{*}$ dapat menentukan atau mencari lintasan terpendek pada sistem. Pengujian meliputi pencarian jalur atau lintasan terpendek dari aplikasi yang telah dibuat dengan hasil perhitungan manual. 


\section{Pengujian Manual}

Berikut ini adalah contoh hasil dari perhitungan manual pencarian rute terdekat toko bangunan di kota Bogor dengan menggunakan algoritma $A^{*}(A-S t a r)$. Dalam implementasi pencarian rute ini akan dicari rute terdekat dari titik awal yang menggunakan marker $\mathrm{S}$ sebagai symbol titik awal, menuju marker $\mathrm{H}$ sebagai titik tujuan seperti diperlihatkan pada Gambar 5 berikut ini:

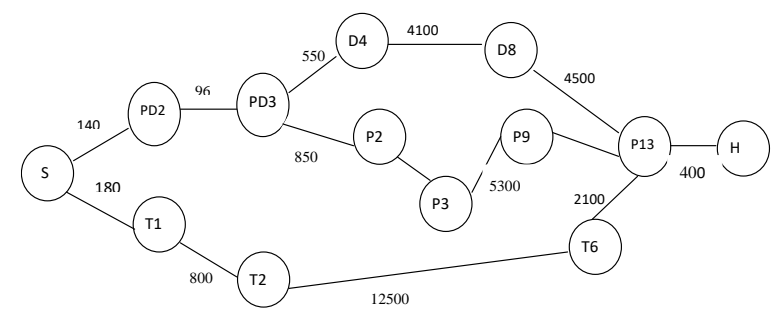

Gambar 5. Rute rumah sakit dalam bentuk graf

\section{Proses Pencarian RuteTerdekat}

1. Menentukan jarak antara dua titik koordinat yang berhubungan. Pada tabel 2 dapat dilihat jarak antara dua titik koordinat dimana jarak tersebut diasumsikan kedalam $g(n)$.

Tabel 1. Jarak Antara Dua Titik Koordinat $g(n)$

\begin{tabular}{|c|c|c|}
\hline Id titik asal & Id titik tujuan & Jarak $\mathrm{g}(\mathrm{n})$ \\
\hline S & T1 & 180 \\
\hline S & PD2 & 140 \\
\hline T1 & T2 & 800 \\
\hline T2 & T6 & 12500 \\
\hline T6 & P13 & 2100 \\
\hline PD2 & PD3 & 96 \\
\hline PD3 & P2 & 850 \\
\hline P2 & P3 & 550 \\
\hline P3 & P9 & 5300 \\
\hline P9 & P13 & 3400 \\
\hline PD3 & D4 & 550 \\
\hline D4 & D8 & 4100 \\
\hline D8 & P13 & 4500 \\
\hline P13 & H & 400 \\
\hline
\end{tabular}

2. Menentukan titik koordinat longitude dan latitude pada pada peta

Untuk menentukan titik koordinat suatu node, pada google maps pilih lokasi awal dan lokasi tujuan kemudian diambil titik-titik lokasi persimpangan jalan yang akan dilalui kemudian dari koordinat longitude latitude tersebut di konversi kebentuk ecimal.Adapun hasil penentuan titik koordinat setiap node/ titik adalah sebagai berikut: 
KOMPUTASI (Jurnal IImiah IImu Komputer dan Matematika)

Vol.16, No.1, Januari 2019, Hal. 235 - 253

P-ISSN: 1693-7554, E-ISSN: 2654-3990

https://journal.unpak.ac.id/index.php/komputasi

Tabel 2. Titik koordinat setiap node/titik

\begin{tabular}{|c|l|l|}
\hline Node & Titik koordinat longituddan latitude & \multicolumn{1}{|c|}{ Konversi ke decimal } \\
\hline S & $-6.599549,106.812832$ & $696033.84,9275013.6$ \\
\hline T1 & $.600411,106.811906$ & $700224.83,9270155.4$ \\
\hline T2 & $-6.603704,106.807732$ & $699761.87,9269792.86$ \\
\hline T6 & $-6.562756,106.796167$ & $698499.08,9274326.39$ \\
\hline PD2 & $-6.599750,106.813000$ & $700346.09,9270228.07$ \\
\hline PD3 & $-6.600454,106.813537$ & $700405.2,9270149.99$ \\
\hline P2 & $-6.605036,106.807458$ & $699731.03,9269645.65$ \\
\hline P3 & $-6.604463,106.806976$ & $699677.95,9269709.22$ \\
\hline P9 & $-6.582802,106.787627$ & $697543.97,9271386.6$ \\
\hline P13 & $-6.556502,106.777279$ & $696412.39,9275025.53$ \\
\hline D4 & $-6.597896,106.817592$ & $600854.72,9270431.27$ \\
\hline D8 & $-6.569014,106.809234$ & $69641.89,9273629.04$ \\
\hline H & $-6.557431,106.773897$ & \\
\hline
\end{tabular}

Tabel 3. Perhitungan $g(n), h(n)$ dan $f(n)$ dengan algoritma $A^{*}$

\begin{tabular}{|c|c|c|c|c|c|}
\hline Node & $\begin{array}{c}\text { Titik koordinat konversi ke } \\
\text { decimal }\end{array}$ & Jarak antar node & $g(n)$ & $h(n)$ & $f(n)$ \\
\hline \multirow[t]{7}{*}{$\mathrm{S}$} & $\begin{array}{c}\mathrm{T} 1 \\
700224.83,9270155.4\end{array}$ & $\mathrm{~S}-\mathrm{T} 1=180$ & 180 & 6345.90 & 6525.90 \\
\hline & $\begin{array}{c}\text { T2 } \\
699761.87,9269792.86\end{array}$ & $\begin{array}{l}\mathrm{T} 1-\mathrm{T} 2=800 \\
\mathrm{~T} 2-\mathrm{S}=980\end{array}$ & 980 & 6340.13 & 7230.13 \\
\hline & $\begin{array}{c}\text { T6 } \\
698499.08,9274326,39\end{array}$ & $\begin{array}{l}\text { T2-T6 = } 12500 \\
\text { T6-S = } 13480\end{array}$ & 13480 & 2532.67 & 16012.67 \\
\hline & $\begin{array}{c}\mathrm{P} 13 \\
696412.39,9275025.53\end{array}$ & $\begin{array}{l}\text { T6-P13 = } 2100 \\
\text { T6-S }=15580\end{array}$ & 15580 & 387.93 & 15967.93 \\
\hline & $\begin{array}{c}\mathrm{D} 4 \\
700854.72,9270431.27\end{array}$ & $\begin{array}{l}\text { PD3-D4 = 550 } \\
\text { D4-S = 786 }\end{array}$ & 786 & 6586.87 & 7372.87 \\
\hline & $\begin{array}{c}\text { D8 } \\
699941.89,9273629.04\end{array}$ & $\begin{array}{l}D 4-D 8=4280 \\
D 8-S=5066\end{array}$ & & 4113.14 & 9179.14 \\
\hline & $\begin{array}{c}\text { PD2 } \\
700346.09,9270228.07\end{array}$ & S-PD2 $=140$ & 140 & 6372.82 & 6512,82 \\
\hline \multirow[t]{2}{*}{ Node } & $\begin{array}{c}\text { Titik koordinat konversi ke } \\
\text { decimal }\end{array}$ & Jarak antar node & $g(n)$ & $h(n)$ & $f(n)$ \\
\hline & $\begin{array}{c}\text { PD3 } \\
700405.2,9270149.99\end{array}$ & $\begin{array}{l}\text { PD2-PD3 = } 96 \\
\text { S-PD3 = } 236\end{array}$ & 236 & 6470.32 & 6706.32 \\
\hline
\end{tabular}

Pemantauan Kesehatan Gizi Ibu Hamil Dilihat dari Pertambahan Berat dan Pengukuran Lingkar Lengan Atas (LILA) Berbasis E-Digital (Yuli Wahyuni, Akbar Sugih Miftahul Huda) 


\begin{tabular}{|c|c|c|c|c|}
\hline $\begin{array}{c}\text { P2 } \\
699731.03,9269645.65\end{array}$ & $\begin{array}{l}\text { PD3-P2 = 850 } \\
\text { P2-S = } 1086\end{array}$ & 1086 & 6442.12 & 7528.12 \\
\hline $\begin{array}{c}\text { P3 } \\
699731.03,9269645.65\end{array}$ & $\begin{array}{l}P 2-P 3=550 \\
P 3-S=1636\end{array}$ & 1636 & 6359.61 & 7995.61 \\
\hline $\begin{array}{c}\mathrm{P9} \\
697543.97,9271386.6\end{array}$ & $\begin{array}{l}\text { P3-P9 }=5300 \\
\text { P9-S }=6936\end{array}$ & 6936 & 3844.77 & 3844.77 \\
\hline $\begin{array}{c}\mathrm{P} 13 \\
696412.39,9275025.53\end{array}$ & $\begin{array}{l}\text { T6-P13 = 2100 } \\
T 6-S=15580\end{array}$ & 15580 & 387.93 & 15967.93 \\
\hline & $\begin{array}{l}\text { P9-P13 = 3400 } \\
\text { P13-P9-P3-P2-PD3- } \\
\text { PD2-S= 10336 }\end{array}$ & 10336 & & 10723.93 \\
\hline & $\begin{array}{l}\mathrm{P} 13-\mathrm{D} 8=4500 \\
\mathrm{P} 13-\mathrm{D} 8-\mathrm{D} 4-\mathrm{PD} 3-\mathrm{PD} 2- \\
\mathrm{S}=9566\end{array}$ & 9566 & & 9953.93 \\
\hline $\begin{array}{c}\mathrm{H} \\
696037.95,9274924.11\end{array}$ & $\begin{array}{l}\mathrm{H}-\mathrm{P} 13 \\
=400 \\
\mathrm{H}-\mathrm{S} \text { lewat } \mathrm{P} 3=10086\end{array}$ & 10086 & & 10086 \\
\hline
\end{tabular}

\section{Perhitungan untuk mencari nilai $f(n)$}

Untuk mendapatkan jalur terpendek menuju RS Hermina dengan langkah-langkah sebagai berikut:

a) Dimulai dari start node ( $\mathrm{S}=$ Universitas Pakuan), queuenya adalah Queue $\{[\mathrm{S}]\}$. Terdapat 2 node dari $S$ yaitu node T1 dan PD2, cari nilai $f(n)$ terkecil dari node tersebut, $f(n)$ T1 merupakan $f(n)$ terkecil maka node T1 sebagai current-node. Hasil queuenya adalah Queue $\{[S, T 1, g(n) 180 f(n)$ 6525.90] [S, PD2, $g(n) 140 f(n) 6512]\}$

b) Lakukan tahap berikutnya seperti tahap a)

c) Hasil Queue adalah sebagai berikut :

- Queue $\{[S]\}$.

- Queue $\{[S, T 1,180 f(n) 6525.90]$ [S,PD2,Jarak $140 f(n) 6512]\}$

- Queue $\{[S, T 1,180 f(n) 6525.90]$ [S,PD2,Jarak $140 f(n) 6512]\}$

- Queue $\{[S, T 1,(180) f(n) 6525.90][S, P D 2, P D 3 g(n)=(140+96) f(n) 6706.324]\}$

- Queue $\{[S, T 1, T 2(180+800) f(n) 7230.13]$ [S,PD2,PD3 Jarak $(140+96) f(n) 6706.324]\}$

- Queue \{ [S,T1, T2 (180+800) $f(n)$ 7230.13] [S,PD2,PD3,D4 Jarak $(140+96+550) f(n)$ 7372.87] [S,PD2,PD3,P2 Jarak $(140+96+850) f(n) 7528.12]\}$

- Queue $\{[S, T 1$, T2,T6 $g(n)=(180+800+12500) f(n) 16012.67$ ] [S,PD2,PD3,D4 $g(n)=$ $(140+96+550) f(n) 7372.87213][S, P D 2, P D 3, P 2 g(n)=(140+96+850) f(n) 7528.12]\}$

- Queue \{ [S,T1, T2,T6 (180+800+12500) $f(n)$ 16012.67 ] [S,PD2,PD3,D4,D8 Jarak $(140+96+550+4280) f(n) 9179.144$ ] [S,PD2,PD3,P2,P3 Jarak $(140+96+850+550=1636)$ $f(n)$ 7995.613] $\}$

- Queue \{ [S,T1, T2,T6 (180+800+12500) $f(n)$ 16012.67 ] [S,PD2,PD3,D4,D8 Jarak $(140+96+550+4280) \quad f(n) \quad 9179.144 \quad] \quad[S, P D 2, P D 3, P 2, P 3, P 9 \quad$ Jarak (P9$S=5300+550+850+96+140=6936) f(n) 10780.77$ ] $\}$

- Queue \{ [S,T1, T2,T6 $(180+800+12500) \quad f(n) 16012.67$ ] [S,PD2,PD3,D4,D8,P13 $g(n)=(4500+4280+550+96+140=9566) \quad f(n) 9953.93] \quad[S, P D 2, P D 3, P 2, P 3, P 9 \quad g(n)=(P 9-$ $S=5300+550+850+96+140=6936)$ $f(n) 10780.77]\}$

- Queue $\{[S, T 1$, T2,T6 $(180+800+12500) f(n)$ 16012.67 ] [S, PD2, PD3, D4, D8, P13, H $g(n)=(400+4500+4280+550+96+140=10086) \quad f(n) 10086] \quad$ [S,PD2,PD3,P2,P3,P9 $g(n)=(5300+550+850+96+140=6936) f(n) 10780.77]\}$

d) Proses dihentikan karena sudah didapatkan node tujuan dengan $f(n)$ terkecil. 
e) Adapun hasil jalur dari Universitas Pakuan menuju RS Hermina ang didapatkan dengan metode algoritma $\mathrm{A}^{*}$ adalah dari S-PD2-PD3-D4-D8-P13-H.

Hasil pencarian jalur terpendek menggunakan algoritma A* ditunjukan pada Gambar 6.

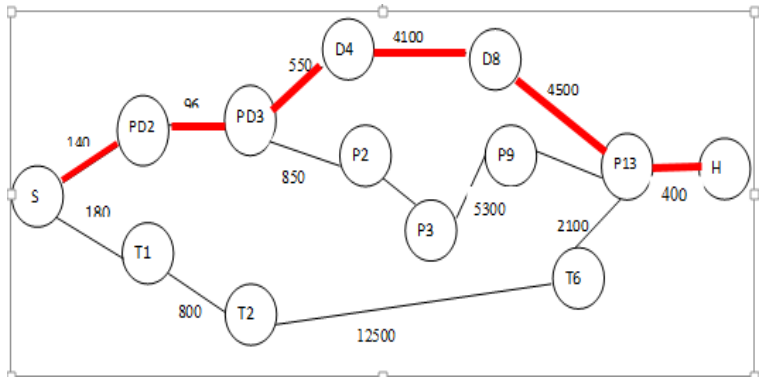

Gambar 6. Hasil Analisis Jalur Terpendek pada rumah sakit Hermina Kota Bogor

\section{Kesimpulan}

Penerapan algoritma $A^{*}$ untuk pencarian jalur terpendek menuju rumah sakit di Kota Bogor dibangun dengan menggunakan software Android Studio, dengan bahasa pemrograman Java dan XML untuk user interface. Adapun tahapan penelitian dengan menggunakan model SDLC, dengan tahapannya meliputi perencanaan sistem, analisis sistem, perancangan, implementasi dan uji coba. Penerapan Algoritma $A^{*}$ pada aplikasi ini dapat memudahkan dalam menentukan jalur terpendek menuju rumah sakit di Kota Bogor. Aplikasi ini dijalankan pada sistem android, sehingga dapat memudahkan user untuk mengakses dimanapun dan kapanpun.

\section{Referensi}

[1] Irsyad M dan Rasila E. 2015. Aplikasi pencarian lokasi gedung dan ruangan Universitas Islam Negeri Sultan Syarif Kasim Riau pada platform Android menggunakan algoritma AStar( $\left.A^{*}\right)$, Jurnal CorelT, 1 (2), Desember 2015.ISSN:2460-738X.

[2] Putra, R. D., Aswin, M., \& Djuriatno, W. 2012. Pencarian Rute Terdekat Pada Labirin Menggunakan Merode $\mathrm{A}^{*}$. Jurnal EECCIS, 6(2).

[3] Juhara, Zamrony P. 2016. Panduan Lengkap Pemrograman Android. ANDI. Yogyakarta.

[4] Imam Ahmad, Wahyu Widodo. 2017. Penerapan Algoritma A Star $\left(A^{*}\right)$ pada GamePetualangan Labirin Berbasis Android. Khazanah Informatika. 3(2): 57-62

[5] Tosida, E, T., Walujo, A, D., Ardiansyah, D., dan Yuliani. 2018. Media Belajar Batik Berbasis Teknologi Augmented Reality. Prosiding Kevin Prathama Nugraha1, Dr. Ir. BambangHidayat, IPM2, Leanna VidyaYovita, S.T., M.T. 2017. PerancanganAplikasi Dan ImplementasiPencarianLokasiTerdekatPadaKawasan Telkom University Berbasis Android. e-Proceeding of Engineering: 4(2) Agustus 2017. ISSN: 2355-9365.

[6] Muh. Yamin, Moh. Bandrigo Talai. 2017. Aplikasi Pencarian Jalur Terpendek Pada Rumah Sakit Umum Bahteramas Menggunakan Algoritma A* (A-Star). Jurnal Informatika 9(2): 1065-1078

[7] Yoki Firmansyah, Udi. 2018. Penerapan Metode SDLC Waterfall Dalam Pembuatan Sistem Informasi Akademik Berbasis Web Studi Kasus Pondok Pesantren Al-Habi Sholeh Kabupaten Kubu Raya, Kalimantan Barat. Jurnal Teknologi \& Manajemen Informatika 4(1): 184-191. 